\title{
Rôle d'une levure dans un accident de fabrication chez des fromages à pâte fraîche
}

\author{
par \\ J. GUIRAUD et P. GALZY \\ Laboratoire de Microbiologie, \\ Sciences et Technologies des Industries Alimentaires, \\ Université des Sciences et Techniques du Languedoc \\ 34060 Montpellier Cedex
}

\section{INTRODUCTION}

A la suite d'accidents de fabrication survenus dans une fromagerie sur deux types de fromages à pâte fraîche (type petit suisse et type fromage frais) nous avons été amenés à effectuer une analyse microbiologique, afin de déterminer la nature de l'agent responsable et de pouvoir y remédier. Dans les deux cas les symptômes étaient voisins : goût piquant, gonflement de l'emballage, apparition de bulles de gaz dans la pâte.

\section{MATERIEL ET METHODES}

L'analyse microbiologique a consisté en un examen microscopique à l'état frais et par la coloration de Gram, en une numération de la flore totale sur le milieu MRS (Man, Rogosa, Sharpe, 1960), en celle des coliformes par la méthode au bouillon lactosé bilié au vert brillant (Mackenzie et al., 1948), en celle des streptocoques fécaux sur milieu de Hajna et Perry (1943) confirmé par culture sur milieu de Litsky (1955) et en celle de la flore fongique (levures et champignons) sur milieu de Sabouraud, chloramphénicol (Ajello, 1957).

La recherche des Salmonella (Arnold, 1955) et celle des staphylocoques pathogènes (Chapman, 1945) a été également effectuée. La levure isolée a été étudiée et déterminée selon les techniques décrites par Lodder (1970).

\section{RESULTATS ET DISCUSSION}

Un examen par la coloration de Gram n'a permis la mise en évidence que de bactéries Gram + dont la présence est normale (lactobacilles 
et streptocoques). Par contre l'examen à l'état frais a permis la mise en évidence de nombreuses levures.

Le tableau suivant représente les résultats de l'analyse.

\begin{tabular}{l|c|c}
\hline \multirow{1}{*}{ Tests } & \multicolumn{2}{|c}{ Nombre de cellules par gramme } \\
\cline { 2 - 3 } & Type fromage frais & Type petit suisse \\
\cline { 2 - 3 } & & \\
\hline Flore totale & $5.10^{8}$ & $10^{8}$ \\
Coliformes & 1 à 10 & 1 à 10 \\
$\begin{array}{l}\text { Streptocoques fécaux } \\
\text { Flore fongique : } \\
\text { Levures } \\
\text { Champignons }\end{array}$ & $10^{2}$ à $5.10^{2}$ & $10^{2}$ à $5.10^{2}$ \\
& $10^{7}$ & $5.10^{5}$ \\
& 1 & 2 \\
\hline
\end{tabular}

Les résultats montrent une flore totale abondante ce qui est normal. Le taux des coliformes est tolérable. Par contre, celui des streptocoques fécaux est anormalement élevé.

Il n'a pas été trouvé de Salmonella et de staphylocoques entérotoxiques. La présence d'une très forte flore de levures constitue pour l'essentiel la cause de l'accident observé.

De nombreuses colonies de levures ont été prélevées et identifiées ; toutes se sont révélées être des Torulopsis sphaerica. Cette espèce considérée comme la forme imparfaite de Kluyveromyces lactis est dotée du pouvoir de fermenter le lactose : ceci concorde avec la nature de l'accident mis en évidence.

Un examen de la chaîne de fabrication a permis de trouver les points où s'effectuait la contamination. Un nettoyage a permis d'éliminer les accidents.

\section{R és u m é}

Les accidents de fabrication (gonflement avec bulles de gaz et goût piquant) observés sur deux fromages à pâte fraîche sont dus à une forte contamination par la levure Torulopsis sphaerica. 


\section{S u m m a r y}

Making flaws (gaz bulging and sour taste) observed in two fresch cheeses depend on yeast contamination by Torulopsis sphaerica.

Reçu pour publication en avril 1976.

\section{Bibliographie}

Ajello (L.) (1957). - Cultural methods for human pathogenic Fungi. J. Chron. dis., $5,545$.

ARNold (J. B.) (1955-56). - A modified technique for the examinate of sewage swabs for Salmonella organisms. J. Med. Lab. Technol., 13, 540.

Chapman (G. H.) (1945). - The significance of sodium chloride in studies of Staphylococci. J. Bact., 50, 201.

Hajna (A.) and Perry (C.) (1943). - Comparative study of presumptive and confirmative media for bacteria of the coliform group and for faecal streptococci. Ann. J. Publ. Hlth., 33, 550.

Litsky (W.), Mallmann (W.) and Fifield (C.) (1955). - Comparison of the most probable numbers of E. coli and enterococci in river waters. Ann. J. publ. HLTH., 45, 1049.

Lodder (J.) (1970). - The Yeast. North Holland Publishing Company, Amsterdam.

Mackenzie (E. F. W.), Windle Taylor (E.), Gilbert (W. E.) (1948). - Recent experiens in the rapid identification of Bacteria coli type I. J. Gen. Microbiol., 2, 197.

Man (J. C.) DE, Rogosa (M.), Sharpe (M. E.) (1960). - A medium for the cultivation of lactobacilli, J. Appl. Bact., 32, 130. 